\title{
Organisational Factors Affecting Use of Information and Communication Technology for Staff Recruitment in South-Western Nigeria
}

\author{
Dr. Samuel Ayodeji OMOLAWAL* Prof. Ifeanyi Prinuel ONYEONORU \\ Department of Sociology, Faculty of the Social Sciences, University of Ibadan, Ibadan, Nigeria
}

\begin{abstract}
This study investigated organisational factors affecting the use of Information and Communication Technology (ICT) for staff recruitment in south-western Nigeria. The study was guided by World System and Rogers' Diffusion of Innovation theories. Study population was Human Resource Management (HRM) Practitioners, selected through random and purposive sampling techniques. Questionnaire was used to elicit data from 1,032 respondents and in-depth interviews with 20 other participants. Quantitative and quantitative data were analysed with descriptive statistics; chi square test at 0.05 level of significance and content analysis respectively. The study revealed that the financial position of the organisation (85.1\%), frequency of recruitment (73.4\%), size of organisations (77.4\%), and the status of HR functions (75\%) affected the adoption of ICT for staff recruitment in the study location. There was a significant relationship between location of organisation and adoption of erecruitment $\left(\mathrm{X}^{2} \mathrm{t}=3.588, \mathrm{X}^{2} \mathrm{c}=11.070, \mathrm{df}=5, \mathrm{P}<0.005\right)$. HRM Practitioners are challenged to identify both infrastructural and organisational factors capable of enhancing their level of utilisation of ICT for staff recruitments. Keywords: Recruitment, Selection, Information and Communication Technology, Human Resource Management, Organisation.
\end{abstract}

DOI: $10.7176 / \mathrm{EJBM} / 13-6-13$

Publication date:March $31^{\text {st }} 2021$

\section{Introduction}

The world today is dominated by the forces of technology which permeate every aspect of life and human activities. The term 'technology' refers to every ingredient and element of knowledge which can help to convert materials into goods; create improved or totally new products; make available more efficient services, and provide more advanced and potent knowledge. The changes rapidly occurring in industrial development and the global economy are driven by three waves of technology namely materials, biotechnology and, information and communication technology (ICT). Out of these three, the last is the most influential, affecting almost every aspect of human lives and activities. Taking for example, the internet is said to have revolutionized people's ways of collaboration and communication considering the services it offers across the globe. Some of these services may include electronic mails; file transfer protocol, Gopher, Telnet among others (Ajayi, 2004). ICT, an acronym that stands for Information and Communications Technology, is a complex and combination of artefacts, techniques and knowledge available for solving human problems on information and the way it is communicated. A major feature is the employment of electronic means to store, process and communicate information rather than the mechanical means. Sometimes, it is simply termed as the use of technology to handle information and aid communication (Stephenson, 1997; Dauda, 2007; Omolawal \& Onyeonoru, 2018).

In the business world in general, the internet and other ICT tools have changed the way commerce is conducted; providing entirely new platforms for customers and retailers/wholesalers to transact their business, for business ventures to manage the flow of their production inputs as well as market products; and for job candidates and job-recruiters to locate each other. More specifically, in the contemporary world, due to development in science and technology, the electronic media including the computer and the internet, recruitment of job candidates has taken a completely new form. Before this time, jobs were advertised in local media such as magazines, newspapers, company's gazettes and so on. Other electronic media such as radio and television were also used; candidates were required to apply for such jobs by writing formal application and their credentials physically delivered to the recruiting organisations. The practices then slowed down the recruitment processes and limited the geographical spread of candidates. But the pace of technology has made these manual practices outdated.

The effects of technological change on the global economic structure are creating immense transformations in the way industrial organisations and nations organize production, trade goods, invest capital, and develop new products and processes. Sophisticated information technologies permit instantaneous communication among the far-flung operations of global enterprises. New materials are revolutionizing sectors as diverse as construction and communications. Advanced manufacturing technologies have altered long-standing patterns of productivity and employment. Improved air and sea transportation has greatly accelerated the worldwide flow of people and goods and they all point to enhanced changes, competition and turbulence in the global economy. At the level of organisational operations, most activities have been transformed by the utilisation of information and 
communication technology Galtung, (1997). One of such is the human resource management (HRM) function of recruitment, selection and placement.

Today most organisations simply do their recruitment through the internet by advertising vacancies online and requesting qualified and interested candidates to apply and submit their documents online. Some forms of interviews are done online either by answering some technical questions from the organisation's website, through video conferencing, zoom and other platforms. These processes have radically affected the way recruitment exercises are conducted. This is captured by Piabuo et al, (2017) who argues that although there are still changes underway, but it is clear that the internet has dramatically changed the way recruiting industry works. The process of using certain aspects (especially the more sophisticated) of modern information and communication gadgets for staff recruitment is referred to as e-recruitment or online recruitment. This process in general, offers a number of benefits including simplifying of the recruitment process, enhancing speed, ease and comfort in recruitment and saving of costs, more accurate process with minimum human efforts, access to more and wider pool of applicants and so on (Omolawal, 2015).

Empirical studies mostly in more industrialized societies show that the massive growth of information and communication technologies has helped business organisations to enhance increased productivity and business growth through cost saving, simplification of the processes and increase in the speed at which organisational functions such as staff recruitments are conducted, thereby enhancing their efficiencies. The high level of efficiency being recorded has further promoted the level of utilisation among Human Resource (HR) practitioners and organisations in those environments.

Despite the rise in the number of organisations and HR practitioners using the emerging information and communication technologies for staff recruitment especially in the more developed countries, same can not be said about Nigerian business organisations. This is because modern information and communication technologies are being diffused from more technologically developed countries to developing countries like Nigeria, and a cursory look at its global rating in terms of adoption and utilisation shows that Nigeria and other African countries are lagging behind. For example, Africa has $15.3 \%$ of the world population but only $7.0 \%$ of internet connectivity and $15.3 \%$ Internet users in the world. Nigeria has a total internet users of 98,391,456 which represents $50.2 \%$ of the Nigerian population (Internet World Statistics, 2017). As a result, it has not been possible for most African countries including Nigeria to enjoy the numerous benefits of the global information society as well as the information economy in areas such as e-commerce, e-business, online education, e-health, e-recruitment, among others (Kolawole, 2008). Previous studies on utilisation of ICT for organisational activities have been focused largely on infrastructural factors affecting the level of utilisation, with less attention paid to organisational (noninfrastructural) factors. This was the lacuna this study was designed to fill by investigating the organisational factors affecting the use of ICT for recruiting staff in south western Nigeria.

\section{Theoretical Framework}

The world system and diffusion of innovation theories provided the theoretical back-up for the study. World System Theory provides an explanation for the inequality of nations of the world in terms of their level of technological advancement. Nations regarded as belonging to the metropolis or core, are more advanced and possess advanced technology for their operations both at individual and organisational levels. Their ability to access new technology is higher and so they adopt various technologies for their operations for improved efficiency. On the other hand, the periphery countries have low level of technology but they are compelled to be incorporated into the world economy, that is, systemic incorporation translates to the dilemma of technological adoption and dependency in the light of local capacity. Thus they have to depend on the metropolis to acquire such technologies and adopt them for their operations. The theory therefore provides explanation on the basis for spread of technology from the metropolis (centre) to the periphery (Wallerstein, 2000). On the other hand, the theory of diffusion of innovation provides explanation on the processes, reasons and rate at which new ideas and technology spread through cultures. Diffusion of innovation model reveals that individuals must pass through certain stages in the process of adopting new technology; namely awareness, interest, evaluation, trial and adoption or rejection. According to this theory, organisations adopt innovations through two types of innovation-decisions. Firstly collective innovation decisions which happens when members of organisation jointly and collectively decide to adopt a particular innovation. Secondly, the authority innovation decisions which is when only a few individuals in position of power, i.e. the top hierarchy or management team adopts a desired innovation for use in the organisation (Rogers, 2003).

Applied to the study, the world system theory provides explanation on why Nigeria, as a developing country has to depend on other more developed societies for the acquisition of her information and technological needs, while the diffusion of innovation theory provides explanation on how the decision to adopt technology rests on a few top organisational members who take decision on the operations of the organisation. In this case, it is the responsibility of the management team to take major decisions of this nature. If the human resource is represented at the management team, then it will be easier to argue in favour of adoption of emerging technologies for the 
conduct of HR functions including staff recruitment.

\section{Methodology}

The study design was a cross sectional descriptive survey with the combination of both quantitative and qualitative approaches. The study was conducted in the south western geo-political zone of Nigeria, on 1,052 Human Resource Practitioners selected through a combination of random and purposive sampling techniques. Primary quantitative data were collected through administration of questionnaire on 1,032 respondents randomly selected, plus the conduct of 20 in-depth-interviews with participants purposively selected. On data analysis, the quantitative data were analysed at univariate and bivariate levels using chi square test at 0.05 level of significance, while content analysis was used to analyze the qualitative data. In terms of ethical issues, the researchers respected the privacy, safety and integrity of the respondents and the information they provided was kept very confidential.

\section{Results And Discussions}

\subsection{Socio-demographic variables of Respondents}

On the respondents' socio-demographic characteristics, majority of them, (78.3\%), were male compared with their female counterparts. On the age of the respondents, majority (51.3\%) fell within the age bracket 40-49 years. Taking the marital status of the respondents, majority of them, $(71.5 \%)$ were married, while others were single, separated/divorced or widowed. The majority position here suggests that the study respondents were mature in terms of life and work experiences. The educational qualification revealed that majority of the respondents, $(80.2 \%)$ had university qualifications. This is an indication of a high level of educational attainment capable of enabling them understand the issues in focus in this study. This is also a pointer to their being capable of occupying high statuses and positions in their various organisations. In terms of nature of employment, a total of $80.6 \%$ representing the majority of the respondents were in formal employment, with the rest being self-employed. Out of those in paid employment, $72.4 \%$, representing the majority were in the private sector of the economy. A total of $70.8 \%$ of those in the private sector, were in public liability companies, $19.85 \%$ were in limited liability companies while $9.4 \%$ were in multi-national companies. Majority of those self-employed $(51 \%)$ were in recruitment agencies, while others were either management consultants or HR consultants. The three categories of respondents are closely related as they are all regarded as specialists in HR functions. Overall, 49.5\% (narrow majority) were in the manufacturing sector followed by $48.5 \%$ in the service sector.

\subsection{Organisation-related factors inhibiting use of ICT for staff recruitment.}

The table below presents data in respect of organisational factors that may affect utilisation of ICT for staff recruitment, selection and placement in south-west Nigeria.

Table 1: Frequency Distribution on perceived organisational factors inhibiting use of ICT for Staff Recruitment

\begin{tabular}{|c|c|c|c|c|c|}
\hline \multirow[t]{2}{*}{ Items } & $\begin{array}{l}\text { Strongly } \\
\text { Agreed }\end{array}$ & Agreed & Undecided & Disagreed & $\begin{array}{l}\text { Strongly } \\
\text { Disagreed }\end{array}$ \\
\hline & Freq. / \% & Freq. / \% & Freq. / \% & Freq. / \% & Freq. $/ \%$ \\
\hline $\begin{array}{l}\text { Organisation's financial } \\
\text { capability }\end{array}$ & $461 \quad 44.7$ & $417 \quad 40.4$ & $67 \quad 6.5$ & $66 \quad 6.4$ & 212 \\
\hline $\begin{array}{l}\text { Frequency of recruitment in } \\
\text { organisations }\end{array}$ & $384 \quad 37.2$ & $374 \quad 36.2$ & 4.3 & $169 \quad 16.4$ & 5.9 \\
\hline $\begin{array}{l}\text { Non-Integration of e- } \\
\text { recruitment with HR system }\end{array}$ & 3.7 & $\begin{array}{ll}187 & 18.1\end{array}$ & 21 & $\begin{array}{ll}420 & 40.7\end{array}$ & $366 \quad 35.5$ \\
\hline $\begin{array}{l}\text { Inability to tailor e- } \\
\text { recruitment to organisational } \\
\text { needs }\end{array}$ & 12.6 & $370 \quad 35.9$ & $207 \quad 20$ & $194 \quad 18.8$ & $131 \quad 12.7$ \\
\hline Size of organisations & 30.8 & 36.6 & 3.6 & 20.1 & 8.9 \\
\hline Location of organisation & 23.7 & $\begin{array}{ll}554 & 53.7 \\
\end{array}$ & 3.7 & $\begin{array}{ll}100 & 9.7 \\
\end{array}$ & 9.2 \\
\hline $\begin{array}{l}\text { Status of HR functions in } \\
\text { organisations }\end{array}$ & 30.8 & $\begin{array}{ll}456 & 44.2\end{array}$ & 5.4 & $122 \quad 11.8$ & 7.8 \\
\hline
\end{tabular}

\section{Source: Field survey}

From table 1 above, majority of the respondents $(85.1 \%)$ indicated that financial capability of organisation is a major factor that affects the level of use of ICT for staff recruitment. This suggests that some organisations may not have the desired financial strength to invest in the procurement of the tools needed for the conduct of their staff recruitment exercises. This finding also implies that the financial cost of acquisition seems to outweigh the possible benefits derivable from the use of modern ICT for the recruitment functions. This finding supports Imonhopi, (2010) and Adebayo (2018) who had earlier argued that an important factor limiting the level of utilisation of ICT 
in Nigeria is the issue of funds. According to them, ICT is capital intensive especially when one considers the cost of acquiring tools such as computer, modem, and an account with an Internet Service Provider (ISP). With limited resources, coupled with high cost of production and inflationary rate, it becomes very difficult especially for industrial organisations to provide effective internet connection in their organisations. In the telecommunication sub-sector, a considerate percentage of the software and hardware needed for conducting businesses has to be imported from other parts of the world. Expectedly, the more the local currency falls, the more expensive the costs of ICT tools are, in terms of the value of the local currency. With these problems, most organisations in Nigeria are not able to expand, access infrastructure and latest technology and enjoy the high degree of communication collaboration, resource sharing and other global benefits associated with the use of ICT.

The study also identified frequency of recruitment in organisations as another factor that affects the utilisation of ICT for employee recruitment as evidenced by majority of the respondents (73.4\%). The probable logic behind this is that when recruitment, selections and placement are not conducted on regular basis, it will amount to waste of resources to invest on acquisition of certain ICT facilities and software. Reasons for low frequency of staff recruitment, selection and placement according to Storey, (2007) include low staff turnover, increasing use of casualisation and contract staff, nature of the business among others. In support of the above, a respondent during an IDI session explained that more organisations are capitalizing upon the unemployment situation in the country by using more casual workers who are recruited without any formal interviews process. He speaks further:

People ready to work are waiting there at the gate, and you don't need any formal interview to employ them as casual workers. Also, some organisations depend on contingent workers who are needed just for a particular season of the year. All these affect the frequency of formal recruitment of workers.

\section{(IDI/Male HR Practitioner/Ado Ekiti)}

However, a 51 year old male HR practitioner in Lagos disagreed with the above during an IDI session. He rather expressed the view that the use of emerging ICT is a reflection of adjusting to the changes in the society, and the benefits derivable should override other factors. His words:

'Not embarking on acquisition of modern ICT tools is an indication of unwillingness to adapt to change. These tools provide more efficient services and the benefits they provide must be taken above other factors, even where recruitment is not conducted on regular basis.'

\section{(IDI/Male HR Practitioner/Lagos)}

Furthermore, majority of the study respondents disagreed that integration of e-recruitment with HR systems affects the utilisation of ICT for recruiting staff in work organisations, as evidenced by $40.7 \%$ and $35.5 \%$ who disagreed and strongly disagreed with the statement respectively. This finding is very surprising and falls below expectation of what scholars elsewhere see as an emerging practice in HR systems in other climes (Depardieu and Islam, 2008; Dessler, 2008). This finding also contradicts the position of Reilly and Barber (2006) in their research work where they established that in Ireland, e-recruitment has been fully integrated into the entire Human Resource system. Furthermore, Mathis and Jackson (2006) argue that elements involved in HR integrated system include: an automated management system which provides requisition creation, consideration and approval, and online posting of job vacancies; a recruiting process that includes advertisement, candidates' response, tracking of applicants and online recruitment management to increase and facilitate the quality of applicant pool. It also includes facilities to screen background checks, skills and behavioural evaluation services; and finally, hiring management techniques with software to manage information on job candidates while providing standard workflow. The integration also makes possible the creation of a consonance with other HR functions and linking the process to user departments as well as the chief executive officers of the organisation. This consequently enables the user departments and top officers to observe the recruitment process without interfering, know the status and progress report of the during recruitment and selection exercises. The process also serves as a check on the organisational recruiters thereby enhancing objectivity in the process.

On the question of whether inability to tailor e-recruitment to meet the particular needs of recruitment process constitutes a negative factor affecting utilisation of ICT for staff recruitment, majority $(48.5 \%)$ of the respondents agreed while others did not agree. As many as $20 \%$ of the respondents were undecided, which suggests that probably they did not have an understanding of what the process involves. The majority view however suggests that the respondents actually knew what tailoring e-recruitment to meet the needs of individual organisation implies. The rate of increase in utilisation of modern ICT for staff recruitment is part of the Human Resource Information System (HRIS) involving the use of ICT to cover the recruitment cycle as well as to embrace the entire HR processes such that the processes are integrated, tailored and aligned with the corporate structure for better service delivery. The system allows the Chief Executive and top level officers to be linked into the process to play the role 
of non-participant observers, i.e. observe the process without interfering or disturbing the HR processes. The logic behind this is that since HR activities cut across all departments and sections, there is need to embark on quality services and best practices which will translate to effective human resource management. The system also gives opportunity for transformation of HR functions from support-based into customer-focused and responsive functional activities (Ensher, 2002; Kettley and Reilly, 2003; Storey, 2007).

The study also revealed that the size and location of organisations aare factors constituting impediments to utilisation of ICT in the course of staff recruitment, selection and placement, as indicated by majority of the respondents $(30.8 \%$ and $36.6 \%)$ for size and $(23.7 \%$ and $53.7 \%)$ for location who strongly agreed and agreed respectively. This suggests that small organisations and those in rural or remote areas may decide not to embark on adoption of ICT for staff recruitment. The size and location of an organisation will likely have an effect on the frequency of its recruitment as well as on the financial capability to embark on acquisition of modern tools. A 45 year old female recruiter, during an IDI session, explained further to support this finding. Her words:

\begin{abstract}
Organisations in rural areas may likely not adopt e-recruitment because their catchment areas are the immediate local environments. Why then throwing wide the recruitment net when all they need is within the locality?
\end{abstract}

\title{
(IDI/Female HR Practitioner/Lagos)
}

This statement is quite illuminating. If actually organisations can get their manpower within the local environment, spending the minimum cost appears a more reasonable option for them. Also, candidates from distant locations may not be willing to reside in the rural areas if eventually they are recruited because of the push and pull factors identified with residents in urban centres by demographers. However, another respondent disagreed with the above, claiming that the location of organisations should not be a barrier to utilisation of ICT for staff recruitment. He speaks thus:

The location of organisations has nothing to do with the adoption of technology for operations. Irrespective of the location, technology should be adopted to enhance greater efficiency, and organisations stand to gain from it.

\section{(IDI/Male HR Practitioner/Akure)}

Further cross-tabulation shows a significant relationship between the location of respondents and adoption of e-recruitment for staff recruitment functions, because with the chi square test, at the degree of freedom of 5 and level of significance of $0.05, \mathrm{X}^{2} \mathrm{t}$ is less than $\mathrm{X}^{2} \mathrm{c}\left(\mathrm{X}^{2} \mathrm{t}=3.558, \mathrm{X}^{2} \mathrm{c}=11.070\right)$. The correlation analysis $(\mathrm{R}=1.000$ (.21)) also shows a relationship between location of respondents and adoption of e-recruitment. The implication of this is that location of organisations is a contributory factor responsible for low adoption of ICT for staff recruitment, selection and placement. This supports the views of Onoge (1991) that locations of organisations contribute to the level of adoption of ICT for staff recruitment, selection and placement. Organisations sited in remote areas may not likely invest on ICT tools for their staff recruitment functions because the internet penetration may be low and because the local environment may constitute their major catchment areas in term of human resource needs. This could also be explained in the context of the world system theory (Wallerstein, 2000) that countries located in the periphery have lower level of technology adoption and utilisation than countries in the core zone. Impliedly, organisations in rural areas may not adopt certain technologies as much as those in large towns and cities.

The study also identified the status of HR functions in organisations as a factor affecting the level of usage of ICT for staff recruitment as evidenced by majority (75\%) of the respondents. Where the HR is seen as a strategic partner in the organisation, the respect it will command may translate to provision of modern facilities for its operation. In organisations like this, the HR specialist will likely be a member of the management team and this will provide an opportunity to have a say in organisational resource control and acquisition. However, where the HR is seen as support function or mere staff manager, this low status may affect the willingness to acquire and install sophisticated tools for its operations. This is supported by a respondent during an IDI session:

HR Department is still facing status problems in many Nigerian organisations. This has implications for their working tools and the best practices in HR. The CIPMN is working hard to promote the status of HR practices and this partly accounts for its legal instrument in ensuring all practitioners are duly registered to qualify them for practice.

\section{(IDI/Male HR Practitioner/Ibadan)}

As argued by Snell, et al (2002), where HR Department occupies a high status in the hierarchy of an organisation, the department will simultaneously become more cost efficient, flexible, strategic, and customer 
oriented by leveraging information technology for better services. This is supported further by Oribabor (2000) and the Ministry of Manpower, Singapore (2003) who argue that Human Resource functions should be positioned to ensure a change towards an organisational culture that promotes self-reliance, initiative, and quality internal service standards. Also, Ogunbameru (2008) and Omolawal (2015) opine that with the increasing significance of Human Resource Management as central to the success of organisations, HR Managers and their departments are becoming more involved in organisational strategy including establishment of partnerships with line managers. They go further that HR practitioners are getting to know the needs and goals of the business, its direction, and are helping it in getting there. Consequently, they are playing many more roles such as link with the business objectives, innovative role, adaptor role, enabler role, and monitoring role.

Rogers (2003) in his analysis of diffusion of innovation theory posits that authority-innovation decisions in organisations take place when the decision to adopt an innovation is taken by a group of individuals in positions of authority and power within an organisation. When HR practitioners are seen as strategic partners, they become part of the authority holders and it becomes easier to adopt the use of ICT for HR functions and this will in no doubt promote the level of their functional efficiency. Therefore, the status of HR functions in organisation may affect the level of utilisation of ICT for staff recruitment activities.

Furthermore, during in-depth interview sessions, the nature of employment offered to applicants was also revealed as a factor impinging on the level of utilisation of ICT for staff recruitment. Participants explained that in the contemporary world, many employers across the globe, including Nigeria now prefer casual workers and temporary/contract workers. These categories of people do not need much effort in their recruitment because they are not always taken through the processes of selection which may warrant the use of technology. A respondent speaks further as follows:

\section{Casual and temporary workers do not in most cases go through interviews and other selection processes. Since they are readily available at the gates and are largely unsolicited, employers simply take them in without formal procedures. \\ (IDI/Male HR Practitioner/Lagos)}

This suggests that the emerging employment patterns in the contemporary world and the associated informal recruitment methods have implications for utilisation of ICT for staff recruitments in organisations. Findings from this study support the theoretical framework adopted for the study.

\section{Conclusion}

In conclusion, this study has been able to investigate organisational factors affecting the level of utilisation of ICT for staff recruitment functions. Such factors include the financial capability of organisations, frequency of recruitment in organisations, inability to tailor e-recruitment to organisational needs, size of organisations, location of organisations and the status of HR functions in organisations. It therefore behoves on individual organisations to embark on internal assessment with a view to identifying specific organisational factors militating against their effective use of ICT, especially for their staff recruitment, selection and placement functions. Consequently, HR Practitioners in South west Nigeria are challenged to improve on their professionalism by integrating e-recruitment with the recruitment, selection and placement processes and the general HR functions in their various organisations; this will promote efficiency of service and effective communication during, and after recruitment and selection exercises. Furthermore, HR practitioners are also challenged to step up the quality of their service delivery so as to enhance the status of HR practices in their various organisations: This involves transforming the HR functions from administrative roles and staff managers to strategic partners. This will increase the level of recognition accorded to them and enhance the quality of their working tools including the emerging ICT; and finally, there is need for HR Practitioners to integrate both online and offline recruitment services so that even without using the more sophisticated ICT tools, a higher level of efficiency could still be ensured and HR practitioners must also be ready to tailor the e-recruitment system to meet the particular needs of the recruitment process in respective organisation.

\section{REFERENCE}

Adebayo, S.M. (2018). Survey on Food, Beverage and Tobacco Employers. Unpublished Project, submitted to the Chartered Institute of Personnel Management, Nigeria

Ajayi, S. I. (2004). Issues in Globalization in Africa, the Opportunities and the Challenges. Ibadan Journal of the Social Sciences. 2 (1): 23-30

Dauda, Adeleke. (2007). Research and Development for Organisational Competitiveness: Human Resource Technology Innovation Management, in Management Discoveries, A Quarterly Journal of Management Review Ltd. 1:16-27

Depardieu, Gilles and Islam, Pamela. (2008). Efficient Talent Acquisition through E-recruitment. Being report of 
E-Recruitment Market Assessment 2006 by marketresearch.com

Dessler, Gary. (2008). Human Resource Management. (11 $\left.{ }^{\text {th }} \mathrm{Ed}\right)$. New Delhi: Prentice-Hall Inc.

Ensher, E., Nelson T. and Grant-Vallone, E. (2002). Tales from the hiring line: effects of the Internet and technology on HR processes. Organisational Dynamics. 31: 224-244

Imhonopi, David. (2010). Influence of internet Services on Teaching and Research Output Among Academic Staff of Selected Universities in S/W Nigeria. An unpublished Ph.D. thesis submitted to the Dept of Sociology, University of Ibadan

Internet World Statistics. (2017). Retrieved from Internetstats.com on 28 August, 2018

Kettley, P. and Reilly, P. (2003). E-HR: An Introduction. London: Institute of Employment Studies

Kolawole, T.O. (2008) Information and Communication Technology: A Tool for Organisational Growth and Development, in Ogunbameru, O.A. and Oribabor, E.P. (Eds). Industrial Sociology. Ibadan: Penthouse Publications.

Mathis, L. R., \& Jackson, H. J. (2006). Human Resource Management. Eleventh Edition; USA: South Western Corporation

Ministry of Manpower. (2003). e-HR: Leveraging Technology, Case Study Series. Singapore, 2/2003

Ogunbameru, O.A. (2008). Human Resource Management, in Ogunbameru, O.A \& Oribabor, E.P, (eds). Industrial Sociology. Ibadan: Penthouse Publications.

Omolawal, S.A. \& Onyeonoru, I.P., (2018). Influence of utilisation of ICT for staff recruitment on the quality of staff Recruited in South West Nigeria, Inter. J. Econ. Bus. Manage. 6 (2): 15-23.

Omolawal, S.A. (2015). E-Recruitment: Practices, Benefits and Challenges. Human Resource Management Journal. 7: 76-86.

Oribabor, P. E. (2000). Human Resource Management: A Strategic Planning Approach. Journal of the Institute of Personnel Management of Nigeria. 9:21 - 26

Onoge, F. Omafume. (1991) The Positive use of Quota System in the management of Human Resources. Nigerian Journal of Personnel Management. 5:15-20

Piabuo, S.M., Piendiah, N.E., Njoh Lawrence Njamnshi, L.N., \& Tieguhong, P.J. (2017). The Impact of ICT on the Efficiency of HRM in Cameroonian enterprises: Case of the Mobile Telephone Industry. Journal of Global Entrepreneurship Research. 7(7): 1-18

Reilly, P and Barber, L (2006). E-recruitment: Practices and trends in Ireland. Public Appointment Service, Ireland (accessed from hhht://www.employment studies.co.uk/pubs/summary.php?id=pas 0806 on 28 April, 2017)

Rogers, E. M. (2003). Diffusion of innovations. (5th ed.). New York, NY: Free Press

Snell, S., Stueber, D and Lepak, D., (2002). Virtual HR Department: getting out of the middle, in R. Heneman and D. Greenberger (eds). Human Resource Management in Virtual Organisations. Greenwich: CT. Information Age Publishing

Stephenson, Dennis. (1997). Information and Communication Technology in UK Schools, (http://rubble.ultalab.anglia.ac.uk/stephenson/-ICTUKIndex.html

Storey, John. (2007). Human Resource Management: A Critical Text ( $3^{\text {rd }}$ Edition). London: Thomson Learning Wallerstein, Immanuel. (2000). The Essential Wallerstein. New York: The New York Press. 